\title{
A New Circuit Model of Small-Signal Amplifier Using MOSFETs in Triple Darlington Topology
}

\author{
Sachchida Nand Shukla and Susmrita Srivastava
}

\begin{abstract}
A small-signal amplifier with three identical MOSFETs in Darlington's topology is proposed and qualitatively analyzed perhaps for the first time. Unlike CSMOSFET amplifiers, the voltage gain of the proposed circuit is found considerably higher than unity. This amplifier can be used to amplify audio range signal excursions swinging in 0.1$2 \mathrm{mV}$ range. In the narrow-band performance range, the proposed amplifier produces simultaneously high voltage and current gains with low harmonic distortion. These properties offer a flexible application range to the proposed circuit as high-voltage-narrow-band amplifier in permissible audiofrequency range. An additional biasing resistance $R A$ is to be essentially used in the proposed circuit to maintain its voltage/current amplification property. Variations in voltage gain as a function of frequency and different biasing resistances, temperature dependency of performance parameters like voltage gain, bandwidth, current gain, input/output noises and total harmonic distortion of the amplifier are perused to provide a wide spectrum to the qualitative studies.
\end{abstract}

Index Terms-Small signal RC coupled amplifiers, darlington amplifiers, common Source MOS amplifiers, triple darlington amplifiers, MOSFET darlington pairs.

\section{INTRODUCTION}

In general, MOS transistors act as good amplifiers for radio frequency integrated circuits when operated in the saturation region (under specific characteristics) and exhibit capacity to provide high voltage, current and power gains [1], [2]. Concurrently 'Common Source MOSFET' has been explored to amplify small-signals with its specific characteristic of high input impedance, low output impedance, high current gain and a voltage gain greater than unity [3]-[6]. Numerous researches explored this MOSFET configuration suitable for developing high speed switching circuits, memory segments, logic gates, buffer amplifiers, power amplifiers and trans-conductance amplifiers [1]-[9]. However, use of CS-MOSFET in Darlington's topology to develop small-signal audio range amplifiers is still to be established [5], [10]. In this sequence, authors developed two small-signal amplifier circuits using MOSFETs in Darlington pair and explored them as high voltage gain and wideband amplifiers respectively [5].

In the present manuscript, authors proposed a novel circuit of high voltage / high current gain audio-range small-

Manuscript received April 27, 2013; revised July 1, 2013.

Sachchida Nand Shukla, Senior member IACSIT, is with the Department of Physics and Electronics of Dr. Ram Manohar Lohia Avadh University, Faizabad-224001, U.P., India (e-mail: sachida_shukla@yahoo.co.in)

Susmrita Srivastava is with the Department of Physics and Electronics of Dr. Ram Manohar Lohia Avadh University, Faizabad - 224001, U.P., India(e-mail: susmrita @ rediffmail.com) signal amplifier by placing identical CS-MOSFETs in Triple Darlington configuration [11].

Dependency of qualitative performance of the proposed amplifier on various biasing parameters, biasing supply and operational frequency is analyzed and compared with that of high voltage gain Darlington pair MOSFET amplifier [5].

\section{CIRCUIT DESCRIPTION}

Present work comprises a qualitative comparison between two different circuits of small-signal amplifiers using identical MOSFETs in Darlington's topology. The first circuit having two identical MOSFETs M1 and M2 in Darlington pair (Fig. 1) is named here as Referenceamplifier whereas the Proposed-amplifier, as depicted in Fig. 2, is obtained by adding an extra MOS transistor M3 in the circuit of reference amplifier. Assembly of three identical MOS transistors in the amplifier circuit of Fig. 2 constitutes a Triple Darlington composite unit [11]. Both the amplifiers include an additional biasing resistance $R_{A}$ in their circuit design [5], [10]-[13] and use potential divider biasing methodology. Suitably selected passive biasing components provide proper DC biasing to amplifiers of Fig. 1 and Fig. 2, the details of which are summarized in Table I.

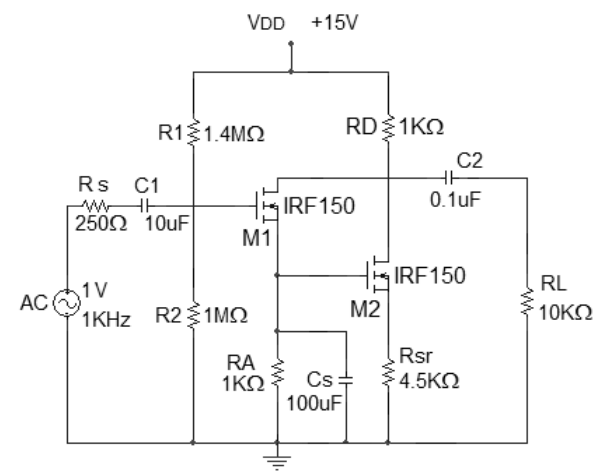

Fig. 1. Darlington pair MOSFET amplifier (Reference amplifier).

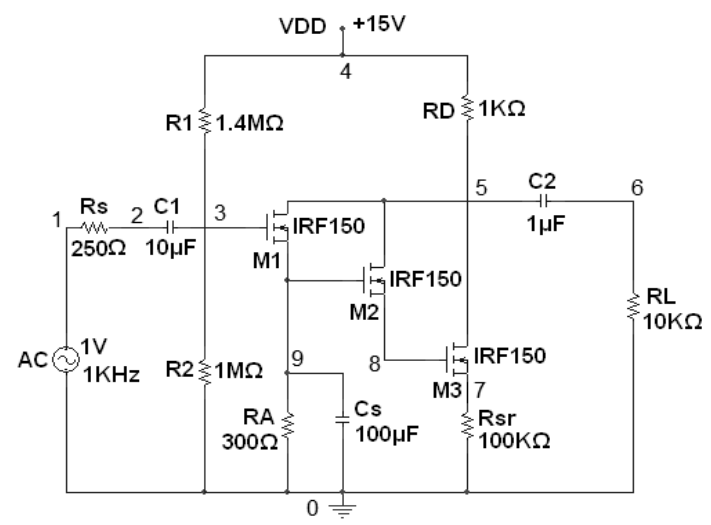

Fig. 2. Triple Darlington MOSFET amplifier (Proposed amplifier). 
PSpice simulation (Student version 9.2) is performed to carry out present investigations [5], [10]-[14]. Observations are procured by feeding the amplifier circuits with $1 \mathrm{~V} \mathrm{AC}$ input signal source, from which, a small-distortion-less AC signal of $1 \mathrm{mV}$ for both the amplifiers at $1 \mathrm{KHz}$ frequency is drawn as input for amplification purpose. The amplifier of Fig. 1 is found to provide undistorted output for $0.1-10 \mathrm{mV}$ $\mathrm{AC}$ input signal at $1 \mathrm{KHz}$ frequency and is biased with $+15 \mathrm{~V}$ DC supply whereas proposed amplifier of Fig. 2 produces distortion-less results for $0.1-2 \mathrm{mV}$ AC input at similar frequency and DC biasing supply.

TABLE I: COMPONENT DETAILS OF THE CIRCUITS UNDER DISCUSSION

\begin{tabular}{|c|c|c|}
\hline COMPONENTS DESCRIPTION & Fig.1 & Fig.2 \\
\hline $\mathrm{M}_{1}, \mathrm{M}_{2}:$ Power MOSFET $\left(\mathrm{V}_{\mathrm{TO}}=2.831\right)$ & IRF150 & IRF150 \\
\hline $\mathrm{M}_{3}:$ Power MOSFET $\left(\mathrm{V}_{\mathrm{TO}}=2.831\right)$ & - & IRF150 \\
\hline RS: Source Resistance & $250 \Omega$ & $250 \Omega$ \\
\hline $\mathrm{R}_{1}$ : Biasing Resistance & $1.4 \mathrm{M} \Omega$ & $1.4 \mathrm{M} \Omega$ \\
\hline $\mathrm{R}_{2}$ : Biasing Resistance & $1 \mathrm{M} \Omega$ & $1 \mathrm{M} \Omega$ \\
\hline $\mathrm{R}_{\mathrm{D}}$ : Drain Biasing Resistance & $1 \mathrm{~K} \Omega$ & $1 \mathrm{~K} \Omega$ \\
\hline $\mathrm{R}_{\mathrm{SR}}$ : Source Biasing Resistance & $4.5 \mathrm{~K} \Omega$ & $100 \mathrm{~K} \Omega$ \\
\hline $\mathrm{R}_{\mathrm{A}}$ : Additional Biasing Resistance & $1 \mathrm{~K} \Omega$ & $300 \Omega$ \\
\hline $\mathrm{R}_{\mathrm{L}}:$ Load Resistance & $10 \mathrm{~K} \Omega$ & $10 \mathrm{~K} \Omega$ \\
\hline $\mathrm{C}_{1}$ : Coupling Capacitor & $10 \mu \mathrm{F}$ & $10 \mu \mathrm{F}$ \\
\hline $\mathrm{C}_{2}$ : Coupling Capacitor & $0.1 \mu \mathrm{F}$ & $1 \mu \mathrm{F}$ \\
\hline$C_{\mathrm{s}}$ : Source By-pass Capacitor & $100 \mu \mathrm{F}$ & $100 \mu \mathrm{F}$ \\
\hline DC Biasing Supply & $+15 \mathrm{~V} \mathrm{DC}$ & $+15 \mathrm{~V} \mathrm{DC}$ \\
\hline $\begin{array}{l}\text { AC input signal range for purposeful } \\
\text { amplification at } 1 \mathrm{KHz} \text { frequency }\end{array}$ & $0.1-10 \mathrm{mV}$ & $0.1-2 \mathrm{mV}$ \\
\hline
\end{tabular}

\section{RESUlTS AND DiscUSSIONS}

The amplifiers of Fig. 1 and Fig. 2 are found to provide fair and distortion-less results for $0.1-10 \mathrm{mV}$ and $0.1-2 \mathrm{mV}$ AC input signals respectively in $100 \mathrm{~Hz}$ to $100 \mathrm{KHz}$ input frequency range at $+15 \mathrm{~V}$ DC biasing voltage. However, when DC biasing to the proposed amplifier is changed to $+12 \mathrm{~V}$, the circuit provides distortion-less results for 0.1 $15 \mathrm{mV} \mathrm{AC}$ input signal in the similar range of frequency.

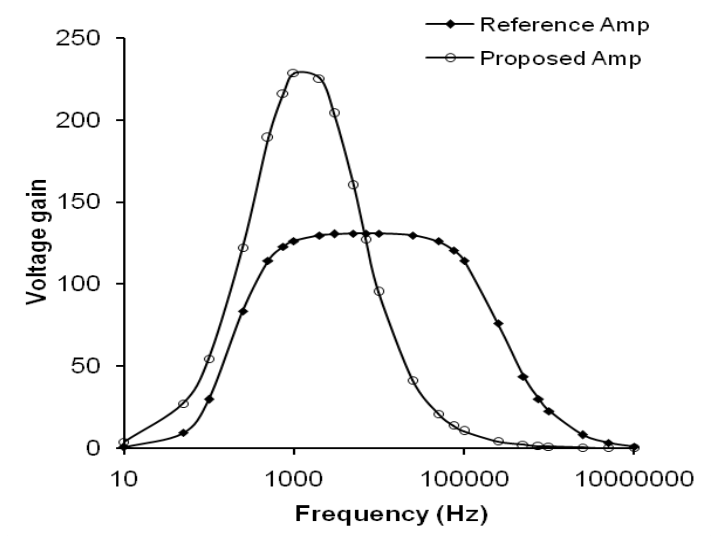

Fig. 3. Variation of voltage gain with frequency.

Fig. 3 shows the variation of voltage gains of respective amplifiers with frequency. Clearly, the proposed circuit holds an improved voltage gain than reference amplifier. The proposed amplifier of Fig. 2 produces 232.12 maximum voltage gain $A_{V G}$ (peak output voltage $V_{O P}=240.28 \mathrm{mV}$ ), $2.65 \mathrm{~K}$ maximum current gain $\mathrm{A}_{\mathrm{IG}}$ (peak output current $\mathrm{I}_{\mathrm{OP}}=$ $24.03 \mu \mathrm{A}$ ) and $4.426 \mathrm{KHz}$ bandwidth (lower-cut-off frequency $\mathrm{f}_{\mathrm{L}}=379.32 \mathrm{~Hz}$ and upper-cut-off frequency $\mathrm{f}_{\mathrm{H}}=4.805 \mathrm{KHz}$ ) with phase reversal in output waveform.

In addition, when the proposed amplifier is biased with
$+12 \mathrm{~V}$ DC supply having similar values of biasing parameters, it crops 184.829 maximum voltage gain $\mathrm{A}_{\mathrm{VG}}$ (peak output voltage $\mathrm{V}_{\mathrm{OP}}=182.039 \mathrm{mV}$ ), $2.5040 \mathrm{~K}$ maximum current gain $\mathrm{A}_{\mathrm{IG}}$ (peak output current $\mathrm{I}_{\mathrm{OP}}=18.204 \mu \mathrm{A}$ ), $5.475 \mathrm{KHz}$ bandwidth $\left(\mathrm{f}_{\mathrm{L}}=313.132 \mathrm{~Hz}\right.$ and $\left.\mathrm{f}_{\mathrm{H}}=5.789 \mathrm{KHz}\right)$. However, reference amplifier of Fig. 1 produces $130.6 \mathrm{~A}_{\mathrm{VG}}$, $7.40 \mathrm{~K} A_{I G}$ and $178.01 \mathrm{KHz}$ bandwidth $\left(f_{L}=293.134 \mathrm{~Hz}\right.$ and $\mathrm{f}_{\mathrm{H}}=178.305 \mathrm{KHz}$ ). Respective values of voltage and current gains logically set the power gain of the proposed and reference amplifiers considerably larger than unity.

Small-signal AC equivalent circuit of the reference amplifier is drawn in Fig. 4. AC analysis of reference amplifier shows that its equivalent output resistance $\mathrm{R}_{\mathrm{O}} \approx \mathrm{R}_{\mathrm{L}} \| \mathrm{R}_{\mathrm{D}}$ is lower $(\approx 909.09 \Omega)$ than the equivalent input resistance $\mathrm{R}_{\mathrm{I}} \approx \mathrm{R}_{1} \| \mathrm{R}_{2}(\approx 0.5833 \mathrm{M} \Omega)$, with a phase reversal in output voltage waveform. In addition, AC voltage gain of the reference amplifier is estimated as following -

$$
A_{V(\operatorname{Re} f .)} \approx \frac{-g_{m 1}\left(1+g_{m 2} R_{s r}-\frac{R_{s r}}{r_{d 2}}\right)}{\frac{1}{R_{0}}+\left(\frac{1}{R_{o}}+\frac{1}{r_{d 1}}\right)\left(g_{m 2} R_{s r}-\frac{R_{s r}}{r_{d 2}}\right)+\left(\frac{1}{r_{d 1}}+\frac{1}{r_{d 2}}\right)}
$$

On the basis of above equation, the approximate value of AC voltage gain of reference amplifier is figured out to be $\approx-131.093$ with computed $r_{d 1}=2.415 \mathrm{~K} \Omega, r_{d 2}=93.22 \mathrm{~K} \Omega$, $\mathrm{g}_{\mathrm{m} 1}=0.144 \mathrm{mho}$ and $\mathrm{g}_{\mathrm{m} 2}=0.0257 \mathrm{mho}$. Negative sign in the expression shows phase reversal of the output voltage which is because the composite unit of MOSFET Darlington pair holds an equivalent CS configuration [1].

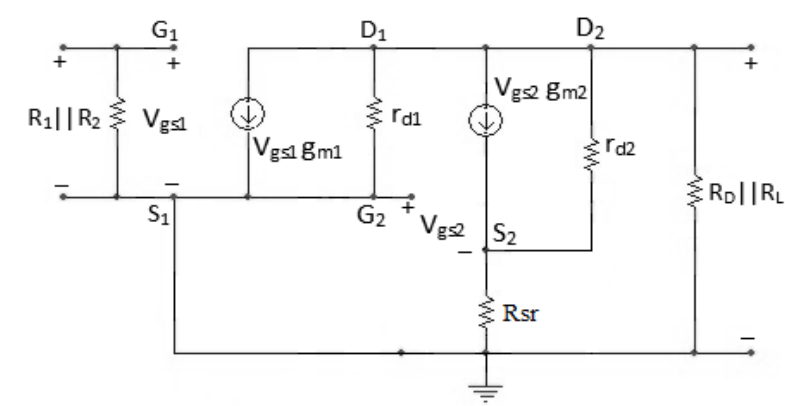

Fig. 4. AC equivalent circuit of reference amplifier.

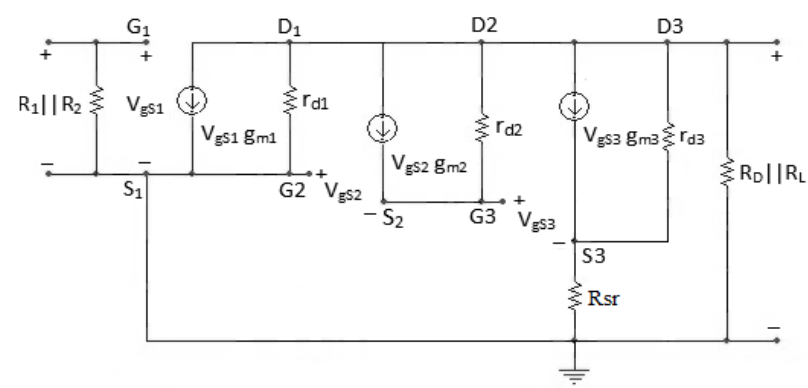

Fig. 5. AC equivalent circuit of proposed amplifier.

In addition, attempts are made to extend the equivalent circuit of Fig. 4 for the proposed amplifier. The upshot is depicted in Fig. 5. Figure suggests that centrally located MOSFET M2 of the proposed amplifier does not allow any significant current to flow from drain to source of M2 with $\mathrm{g}_{\mathrm{m} 2} \rightarrow 0 \mathrm{mho}, \quad \mathrm{I}_{\mathrm{D} 2} \approx 9.27 \times 10^{-14} \mathrm{amp}$ and $\mathrm{V}_{\mathrm{D} 2} \approx 4.12 \times 10^{-8}$ volts, thereby, producing a capacitive effect in the circuit. Presence of Gate-Bulk-Capacitance of $0.207 \mathrm{nF}$ and BulkDrain-Zero-Bias-pn-Capacitance of $3.23 \mathrm{nF}$ due to the 
dedicated location of M2 in proposed circuit generates an intense capacitance.

Therefore, the combination of Miller's capacitance and capacitance due to centrally located MOSFET M2 of the proposed amplifier causes an effective reduction in the bandwidth. Hence, during the analysis of equivalent circuit (Fig.5) for AC voltage gain, M2 of the proposed amplifier would be treated as absent. This estimation suggests following expression for the approximate value of $\mathrm{AC}$ voltage gain of proposed amplifier-

$$
A_{V(\text { proposed })} \approx \frac{-g_{m 1}\left(1+g_{m 3} R_{s r}-\frac{R_{s r}}{r_{d 3}}\right)}{\frac{1}{R_{0}}+\left(\frac{1}{R_{0}}+\frac{1}{r_{d 1}}\right)\left(g_{m 3} R_{s r}-\frac{R_{s r}}{r_{d 3}}\right)+\left(\frac{1}{r_{d 1}}+\frac{1}{r_{d 3}}\right)}
$$

Above equation gives $\mathrm{AC}$ voltage gain of the proposed amplifier to -238.48 with computed $r_{d 1}=48.82 \Omega$, $\mathrm{r}_{\mathrm{d} 3}=272.11 \mathrm{~K} \Omega, \mathrm{g}_{\mathrm{m} 1}=0.262 \mathrm{mho}$ and $\mathrm{g}_{\mathrm{m} 3}=0.005 \mathrm{mho}$.

Total Harmonic Distortion (THD) percentage is also calculated for the reference and proposed amplifiers for 10 significant harmonic terms using following established rule [3], [5].

$$
\% n^{\text {th }} \text { harmonic distortion }=\% D_{n}=\frac{\left|A_{n}\right|}{\left|A_{1}\right|} \times 100 \%
$$

The reference amplifier appears with $1.88 \%$ THD whereas it is observed to be $2.84 \%$ at $+15 \mathrm{~V}$ DC biasing for proposed amplifier. THD for proposed amplifier further reduces to $2.28 \%$ if respective circuit is biased with $+12 \mathrm{~V}$ DC supply. For the mentioned situations, THDs are ranging

\begin{tabular}{|c|c|c|c|c|c|c|}
\hline \multirow[t]{2}{*}{$\begin{array}{c}\text { Temp. } \\
\left({ }^{\circ} \mathrm{C}\right)\end{array}$} & \multicolumn{3}{|c|}{ Fig.1 Amplifier } & \multicolumn{3}{|c|}{ Fig.2 Amplifier } \\
\hline & $\mathrm{A}_{\mathrm{VG}}$ & $\mathrm{A}_{\mathrm{IG}}$ & $\begin{array}{c}\mathrm{B}_{\mathrm{W}} \\
(\mathrm{KHz})\end{array}$ & $A_{V G}$ & $\mathrm{~A}_{\mathrm{IG}}$ & $\begin{array}{c}\mathrm{B}_{\mathrm{W}} \\
(\mathrm{KHz})\end{array}$ \\
\hline-30 & 151.85 & $8.59 \mathrm{~K}$ & 182.53 & 269.26 & $\begin{array}{c}2.74 \\
\mathrm{~K}\end{array}$ & 3.89 \\
\hline-20 & 147.51 & $8.36 \mathrm{~K}$ & 181.67 & 261.71 & $\begin{array}{c}2.72 \\
\mathrm{~K}\end{array}$ & 3.98 \\
\hline-10 & 143.47 & $8.13 \mathrm{~K}$ & 180.71 & 254.65 & $\begin{array}{c}2.70 \\
\mathrm{~K}\end{array}$ & 4.07 \\
\hline 0 & 139.69 & $7.92 \mathrm{~K}$ & 180.06 & 248.04 & $\begin{array}{c}2.69 \\
\mathrm{~K}\end{array}$ & 4.17 \\
\hline 10 & 136.14 & $7.72 \mathrm{~K}$ & 178.06 & 241.84 & $\begin{array}{c}2.67 \\
\mathrm{~K}\end{array}$ & 4.23 \\
\hline 27 & 130.60 & $7.40 \mathrm{~K}$ & 178.00 & 232.12 & $\begin{array}{c}2.65 \\
\mathrm{~K}\end{array}$ & 4.47 \\
\hline 50 & 123.93 & $7.02 \mathrm{~K}$ & 176.44 & 220.41 & $\begin{array}{c}2.62 \\
\mathrm{~K}\end{array}$ & 4.46 \\
\hline 80 & 116.41 & $6.58 \mathrm{~K}$ & 176.34 & 207.15 & $\begin{array}{c}2.58 \\
\mathrm{~K}\end{array}$ & 4.77 \\
\hline 100 & 111.41 & $6.33 \mathrm{~K}$ & 176.09 & 199.35 & $\begin{array}{c}2.55 \\
\mathrm{~K}\end{array}$ & 4.86 \\
\hline 120 & 107.97 & $6.10 \mathrm{~K}$ & 173.82 & 192.25 & $\begin{array}{c}2.53 \\
\mathrm{~K}\end{array}$ & 5.03 \\
\hline
\end{tabular}
within the permissible limit for small-signal amplifiers [3].

Variation of voltage gain, current gain and bandwidth with temperature is also measured and listed in Table II. It is noticed that both variety of gains gradually decreases at increasing temperature for respective amplifiers. This can be associated with the positive temperature coefficient property of Drain-Source resistance [15]. Perhaps Drain-Source resistance of the composite unit rises with temperature which in turn reduces the effective voltage/current gains [15]. On the other hand, bandwidth of reference amplifier reduces but that of proposed amplifier increases with rising temperature. At increasing temperature, perhaps the series combination of composite unit (having an extra MOSFET) capacitance and output coupling capacitor $\mathrm{C}_{2}$ (with $1 \mathrm{uF}$ value) in the proposed amplifier circuit causes reduction in effective circuit capacitance which in turn improves the bandwidth [1], [2], [15].

TABLE III: VARIATION OF INPUT AND OUTPUT NOISES WITH TEMPERATURE

\begin{tabular}{ccccccc}
\hline \hline $\begin{array}{c}\text { Temp. } \\
\left({ }^{\mathrm{O}} \mathrm{C}\right)\end{array}$ & \multicolumn{3}{c}{$\begin{array}{c}\text { Total Output Noise } \\
(\text { Volts } / \sqrt{\mathrm{Hz}})\end{array}$} & \multicolumn{3}{c}{$\begin{array}{c}\text { Total Input Noise } \\
(\text { Volts } / \sqrt{ } \mathrm{Hz})\end{array}$} \\
\cline { 2 - 7 } & $\begin{array}{c}100 \mathrm{~Hz} \\
\left(\times 10^{-9}\right)\end{array}$ & $\begin{array}{c}1 \mathrm{KHz} \\
\left(\times 10^{-10}\right)\end{array}$ & $\begin{array}{c}1 \mathrm{MHz} \\
\left(\times 10^{-14}\right)\end{array}$ & $\begin{array}{c}100 \mathrm{~Hz} \\
\left(\times 10^{-9}\right)\end{array}$ & $\begin{array}{c}1 \mathrm{KHz} \\
\left(\times 10^{-9}\right)\end{array}$ & $\begin{array}{c}1 \mathrm{MHz} \\
\left(\times 10^{-9}\right)\end{array}$ \\
\cline { 2 - 7 }-30 & 1.839 & 8.758 & 1.554 & 1.891 & 1.891 & 3.137 \\
-20 & 1.874 & 8.699 & 1.583 & 1.930 & 1.930 & 3.211 \\
-10 & 1.908 & 8.642 & 1.612 & 1.968 & 1.968 & 3.283 \\
0 & 1.941 & 8.587 & 1.640 & 2.005 & 2.005 & 3.354 \\
10 & 1.974 & 8.534 & 1.667 & 2.042 & 2.041 & 3.423 \\
27 & 2.027 & 8.449 & 1.713 & 2.102 & 2.102 & 3.537 \\
50 & 2.096 & 8.342 & 1.773 & 2.182 & 2.182 & 3.685 \\
80 & 2.182 & 8.216 & 1.849 & 2.282 & 2.282 & 3.868 \\
\hline \hline
\end{tabular}

Respective values of input and output noises for the proposed amplifier at $100 \mathrm{~Hz}, 1 \mathrm{KHz}$ and $1 \mathrm{MHz}$ frequencies are observed and listed in Table III. Usually, resistors and semiconductor devices in electronic circuits are responsible to generate noises during amplification process. Table clearly indicates that levels of input and output noises are significantly low for proposed amplifier and within the permissible limit. Both varieties of noises reduce with elevation of operating frequency. Moreover, it also increases with temperature which is an obvious feature due to generation of more carriers and their higher collision rate at elevated temperature.

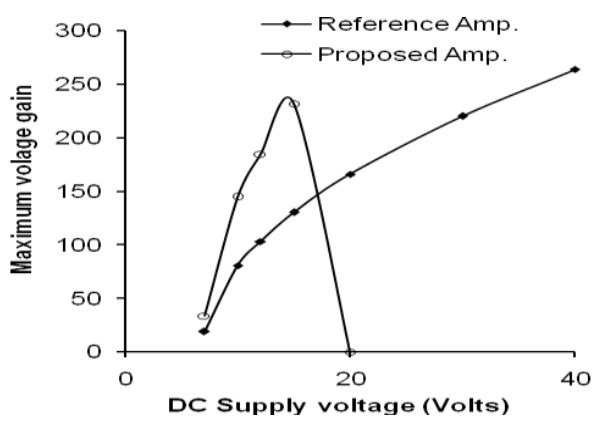

Fig. 6. Variation of maximum voltage gain $A_{V G}$ with $V_{D D}$

Effect of DC supply voltage $\mathrm{V}_{\mathrm{CC}}$ on maximum voltage gain $A_{V G}$ for both the amplifiers is depicted in Fig.6. Figure clearly indicates that MOSFET Darlington pair of reference amplifier and Triple Darlington MOSFET unit of proposed amplifier switch-ON at 7V. Reference amplifier produces a fruitful response in $7-40 \mathrm{~V}$ range of $\mathrm{V}_{\mathrm{CC}}$ whereas this range for proposed amplifier limits to only $7-20 \mathrm{~V}$. $A_{\mathrm{VG}}$ of the reference amplifier rises nonlinearly at increasing values of $\mathrm{V}_{\mathrm{CC}}$ [5]. However it climbs up to a maximum at $15 \mathrm{~V}$ of $\mathrm{V}_{\mathrm{CC}}$ for proposed amplifier, thereafter, decreases rapidly and reaches to a non-significant value at $20 \mathrm{~V}$ of $\mathrm{V}_{\mathrm{CC}}$.

In fact, each MOSFET of the Triple Darlington unit of proposed amplifier holds a threshold voltage $\mathrm{V}_{\mathrm{TO}}=2.831 \mathrm{~V}$. Below $7 \mathrm{~V}$ of $\mathrm{V}_{\mathrm{CC}}$, driving potential to gates of $\mathrm{M} 1$ and $\mathrm{M} 2$ 
MOSFETs are found less than $\mathrm{V}_{\text {TO }}$. This keeps the triple Darlington unit into OFF state. At $7 \mathrm{~V}$ of $\mathrm{V}_{\mathrm{CC}}$, driving gate voltages of M1 and M3 cross the forbidden boundary of $\mathrm{V}_{\text {TO }}$. This brings the composite unit into conducting state. However at $15 \mathrm{~V}$ of $\mathrm{V}_{\mathrm{CC}}$, gate voltages of all the three MOSFETs cross the limiting value of $\mathrm{V}_{\mathrm{TO}}$. This ensures the participation of each MOSFET in the amplification process and therefore voltage gain reaches to a maxim. As $V_{C C}$ increases beyond $15 \mathrm{~V}$, the channel width broadens and causes sudden enhancement in $I_{D}$ which in turn forces for an abrupt voltage drop across the load and distorts the frequency response curve.

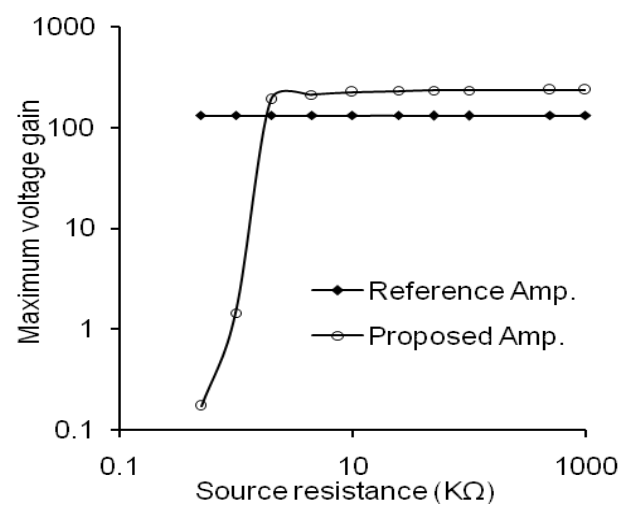

Fig. 7. Variation of maximum voltage gain $A_{V G}$ with source resistance $R_{S R}$.

Variation of maximum voltage gain as a function of source resistance $R_{S R}$ is traced in Fig. 7. For reference amplifier, $A_{V G}$ remains almost unaffected for any change in source resistance [5], [10]. However for proposed amplifier, $\mathrm{A}_{\mathrm{VG}}$ suddenly increases from 1.44 (at $1 \mathrm{~K} \Omega$ ) to187.38 (at 2 $\mathrm{K} \Omega$ ), thereafter, tends to acquire a saturation tendency at higher values of $R_{S R}$. It is also to mention that respective amplifiers show constancy in maximum voltage gain for $\mathrm{R}_{\mathrm{SR}}>10 \mathrm{~K} \Omega$.

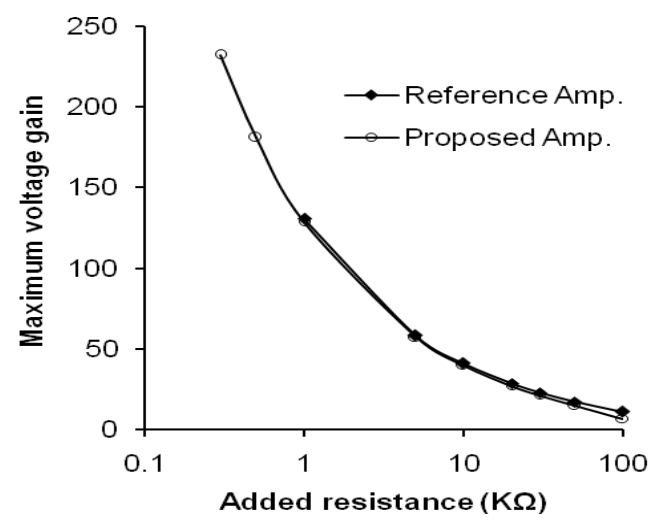

Fig. 8. Variation of maximum voltage gain $A_{V G}$ with added resistance $R_{A}$.

As depicted in Fig. 8, maximum voltage gain decreases almost exponentially at increasing values of additional biasing resistance $\mathrm{R}_{\mathrm{A}}{ }^{(5,10)}$ for both the amplifiers. Voltage gain corresponding to the added resistance $R_{A}$ acquires its maxim at $R_{A} \leq 1 \mathrm{~K} \Omega$ for each amplifier. If $R_{A}$ is removed from the proposed circuit, $\mathrm{A}_{\mathrm{IG}}$ of the amplifier reaches to a non-significant value 0.013 whereas $\mathrm{A}_{\mathrm{VG}}$ reaches below unity to a value 0.729. Conclusively, the presence of additional biasing resistance $\mathrm{R}_{\mathrm{A}}$ in the proposed configuration is essential to establish 'Triple Darlington
MOSFET unit' suitable for amplification of small-signals.

Maximum voltage gain highly depends on drain resistance $R_{D}$ [1], [2], [5], [10]. Its variation with $R_{D}$ is depicted in Fig. 9. For reference amplifier, voltage gain attains a maxim at $R_{D}=3 K \Omega$, thereafter, decreases rapidly and produces distorted output beyond $4 \mathrm{~K} \Omega$ value of $R_{D}$. However, for proposed amplifier with $+15 \mathrm{~V}$ or $+12 \mathrm{~V} \mathrm{DC}$ biasing, the voltage gain attains a maxim at $R_{D}=1 \mathrm{~K} \Omega$, then falls down rapidly and produces distorted output beyond $2 \mathrm{~K} \Omega$.

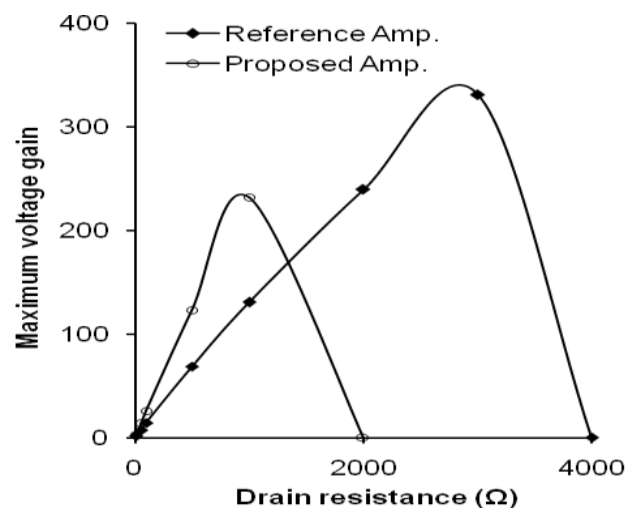

Fig. 9. Variation of maximum voltage gain $A_{V G}$ with drain resistance $R_{D}$.

Variation of maximum voltage gain with load resistance $\mathrm{R}_{\mathrm{L}}$ is also observed but not shown in form of figure. Here, voltage gain gradually rises up to $100 \mathrm{~K} \Omega$ value of $\mathrm{R}_{\mathrm{L}}$ for both the amplifiers, thereafter, tends to acquire a mark of saturation. This rising and saturation tendency of the voltage gain with $\mathrm{R}_{\mathrm{L}}$ is well in accordance of the usual behaviour of small signal amplifiers [2], [5], [6], [10]-[13].

\section{CONCLUSION}

Small-signal Common Source MOSEFT amplifiers hold high current gain as its prominent feature with a voltage gain just greater than unity. However, the proposed smallsignal amplifier, which uses three CS-MOSFETs in a typical Triple Darlington configuration, is explored as high voltage gain amplifier, retaining the high current gain property.

In narrowband performance range (approximately $5 \mathrm{KHz}$ ) this amplifier can effectively process small-signals ranging below $2 \mathrm{mV}$ and its THD at either of the DC supply voltage doesn't exceed beyond $2.84 \%$, which is well within the tolerance limit of small-signal amplifiers. The proposed amplifier produces constant voltage gain at $R_{L}>100 \mathrm{~K} \Omega$ and $\mathrm{R}_{\mathrm{SR}}>10 \mathrm{~K} \Omega$ while shows its optimal performance at $\mathrm{R}_{\mathrm{A}}<1 \mathrm{~K} \Omega$ and $\mathrm{R}_{\mathrm{D}}=1 \mathrm{~K} \Omega$ in $7-15 \mathrm{~V}$ range of $\mathrm{DC}$ supply voltage.

\section{ACKNOWLEDGEMENT}

Authors gratefully acknowledge the facilities provided by the Department of Physics and Electronics, Dr. Ram Manohar Lohia Avadh University, Faizabad, U.P., India for the present investigations.

\section{REFERENCES}

[1] E. Vernon, D. B Ryson, E. S. Orr, and S. N. Mohammad, "Role of supply voltage and load capacitors in the experimental operations of small signal MOSFET amplifiers," Solid State Electronics, vol. 45, no. 12, pp. 2033, 2001. 
[2] E. Vernon, D. Bryson, E. S. Orr, and S. N. Mohammad, "Experimental studies of frequency response of small signal MOSFET amplifiers," Solid State Electronics, vol. 46, no. 2, pp. 287 294, 2002.

[3] R. L. Boylestad and L. Nashelsky, "Electronic Devices and Circuit Theory," Pearson Education Asia, 3rd ed., 2002, pp. 263, 307, 600.

[4] P. McGregor, J. Mena, and C. A. T. Salama, "Small signal high frequency performance of power MOS transistors," Solid State Electronics, vol. 27, no. 5, pp. 419, 1984.

[5] S. Srivastava, B. Pandey, S. N. Tiwari, J. Singh, and S. N. Shukla, "Qualitative analysis of MOS based Darlington Pair Amplifiers," Bulletin of Pure and Applied Science, vol. 30D (Physics), no. 2, pp. 195, 2011 .

[6] E. Vernon, D. Bryson, A. Motayed, and S. N. Mohammad, "Experimental investigation of factors influencing design of small signal CMOS amplifiers," Solid State Electronics, vol. 45, no. 1, pp. 63, 2001.

[7] P. M. Figueiredo and J. C. Vital, "The MOS capacitor amplifier," IEEE Transactions on Circuits and Systems-II: Express Briefs, vol. 51, no. 3, March, 2004

[8] B. Federico, E. A. M. Klumperink, and B. Nauta, "Generating All Two-MOS-Transistor Amplifiers Leads to New Wide-Band LNAs," IEEE Journal of Solid State Circuits, vol. 36, no. 7, pp. 1032, 2001.

[9] M. K. Kazimierczuk, "Class D Voltage-Switching MOSFET Power Amplifier, Electronic Power Amplifications," IEEE Proceeding B, vol. 138 , issue. 6 , pp. 285, 1991.

[10] S. Srivastava, B. Pandey, S. N. Tiwari, J. Singh, and S. N. Shukla, "Development of small-signal high voltage gain amplifier using compound unit of BJT and MOSFET," Acta Ciencia Indica, vol. xxxviip, no. 4, pp. 431, 2011.

[11] S. N. Tiwari and S. N. Shukla, "Qualitative Analysis of Small Signal Modified Darlington Pair and Triple Darlington Amplifiers," Bulletin of Pure and Applied Science, vol. 28D, no. 1, pp. 1, 2009.
[12] A. M. H. Sayed ElAhl, M. M. E. Fahmi, and S. N. Mohammad, "Qualitative analysis of high frequency performance of modified Darlington pair," Solid State Electronics, vol. 46, pp. 593, 2002.

[13] S. N. Tiwari, B. Pandey, A. K. Dwivedi, and S. N. Shukla, "Development of Small-Signal Amplifiers by Placing BJT and JFET in Darlington Pair Configuration," Journal of Ultra Scientist of Physical Sciences, vol. 21, no. 3, pp. 509, 2009.

[14] M. H. Rashid, "Introduction to PSpice Using OrCAD for Circuits and Electronics," Pearson Education, 3rd ed., pp. 255-300, 2004

[15] P. E. J. Dodge, "Power MOSFET Tutorial," Application Note APT0403 Rev B, March 2, 2006

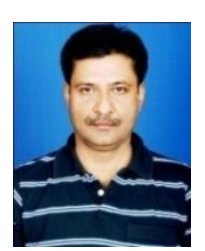

Sachchida Nand Shukla received his M.Sc. and Ph.D. Degrees in Physics (Electronics) from Dr. Ram Manohar Lohia Avadh University, Faizabad in 1988 and 1991 respectively. Presently he is working as Associate Professor in the Department of Physics and Electronics of Dr. Ram Manohar Lohia Avadh University, Faizabad, U.P., India and actively engaged in researches related to the Circuit designing and simulation. During last five years, he published over 35 research papers in International/National journals and Conference Proceedings on various topics of his current research interest.

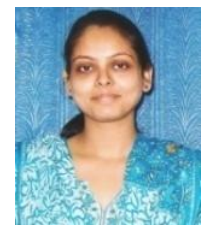

Susmrita Srivastava received her M.Sc. degree in Electronics from Department of Physics and Electronics of Dr. Ram Manohar Lohia Avadh University, Faizabad, U.P., India in 2008. Presently she is pursuing Ph.D. degree in Electronics and published 16 research papers on various topics of Circuit designing and simulation in International /National journals and Conference Proceedings. 